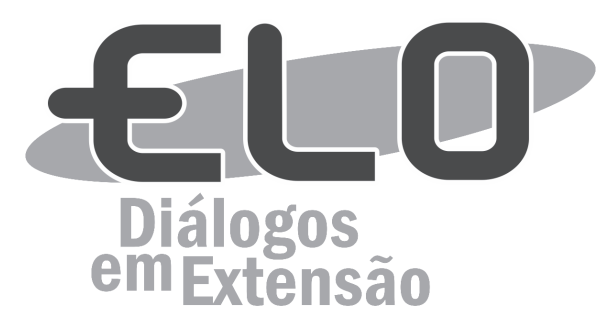

\title{
Educação sexual na promoção do respeito à diversidade sexual e de gênero
}

Ana Paula Leivar Brancaleoni ${ }^{1}$; Rosemary Rodrigues de Oliveira ${ }^{2}$

\begin{abstract}
Resumo: O presente trabalho analisa a trajetória de um Projeto de Extensão que tem por objetivo desenvolver ações de educação sexual promotoras do respeito à diversidade sexual e de gênero. Este estudo está alicerçado em metodologias participativas, que assumem os sujeitos para os quais se direcionam as intervenções, como construtores do processo. São realizadas oficinas com adolescentes, oficinas e assessorias com educadores já inseridos na rede pública e espaços de formação para futuros educadores. Para tanto, adotou-se uma abordagem qualitativa, tendo como objetos de análise os registros dos trabalhos realizados com grupos de alunos e professores e registros de supervisão. Constatou-se que o trabalho com oficinas favorece a clarificação e subjetivação de valores e informações sobre sexualidade e gênero, tanto por parte de adolescentes, quanto por parte de educadores. Entende-se também que o projeto desempenha uma importante função na formação inicial de educadores tornando-os mais capazes para lidar com os temas.
\end{abstract}

Palavras-chave: Educação sexual. Sexualidade. Gênero.

Área Temática: Educação, Gênero.

\section{Sexual education in the promotion of respect for sexual diversity and gender diversity}

\begin{abstract}
A project that has the objective to develop sexual education actions promoting sexual and gender respect has its track analyzed. It based itself in participative methodologies that assume the subjects, to whom the interventions are directed to, as builders of the process. There are workshops carried out with teenagers, workshops and advisories held with educators already inserted in the public education as well as there are training instances for future educators. For the present work, there has been adopted a qualitative approach, being analyzed the records of the actions carried out with students and teachers groups as well as the supervision records. It has been found that actions with workshops favor the clarification and subjectivation of values and information about sexuality and gender, either by students or by educators. It is also understood that the project performs an important role in the early training of educators, making them more able to deal with school themes.
\end{abstract}

Keywords: Sexual education. Sexuality. Gender.

\section{La educación sexual en la promoción del respeto a la diversidad sexual y de género}

Resumen: Se analiza la trayectoria de un Proyecto de Extensión que tiene como objetivo desarrollar acciones de educación sexual para promoverel respeto a la diversidad sexual y de género. Se basa en metodologías de participación de los sujetos, para quienes se direccionan las intervenciones, como constructores del proceso. Se llevan a cabo talleres con adolescentes, al igual que se prestan servicios de asesoramiento con educadores ya introducidos en la red pública y espacios de formación para futuros educadores. Para este estudio, se adopta

\footnotetext{
${ }^{1}$ Professora assistente doutora do Departamento de Economia, Administração e Educação e do Programa de Pós-Graduação em Educação Sexual da FCL/UNESP Campus Araraquara. Universidade Estadual Paulista "Júlio de Mesquita Filho" - Via de Acesso Prof. Paulo Donato Castellane, s/n. 14884-900 - Jaboticabal, SP, fone: (016) 3209-7254. anapaulabrancaleoni@gmail.com

${ }^{2}$ Professora assistente doutora do Departamento de Economia, Administração e Educação da FCAV/UNESP. Professora do Programa de Pós-Graduação em Ensino e Processos Formativos Interunidades da UNESP. oliveirose@fcav.unesp.br
} 
enfoque cualitativo, realizando anális aclaración y la subjetividad de los valores e informaciones sobre la sexualidad y sobre el género, lo cual impacta tanto a los adolescentes, como a los educadores. También se entiende que el proyecto tiene importante función en la formación inicial de los educadores, por lo que acaban siendo más capaces de hacer frente a los problemas.

Palabras clave: Educación sexual. Sexualidad. Género.

\section{Introdução}

Os sentidos atribuídos à sexualidade e ao gênero estão em constante transformação, tanto do ponto de vista dos sujeitos que a experienciam, quanto acerca dos significados sociais partilhados. Ainda assim, existem rígidos padrões estabelecidos de certo/errado, normal/patológico, quando se trata da sexualidade e do gênero, sendo que são representados de forma naturalizada, universal e ahistórica. Conforme aponta Bento (2011, p. 551), vive-se em um sistema heteroterrorista, em que aquilo que é inscrito e determinado em um campo discursivo, é tomado como o natural e "original".

Ressalta-se que o ambiente escolar é um espaço permeado pela sexualidade e pelas questões de gênero. A escola é um lugar de informação e formação, no qual estão presentes todas as áreas do conhecimento, de forma ordenada, que constituem um "curriculum", um percurso a ser percorrido pelo aluno, bem como um conjunto de relações sociais e humanas. Mais do que salas, prédio, alunos e professores, uma escola é fruto das relações que nela se dão, participando da constituição da identidade dos indivíduos que dela participam (SEFFNER, 2011).

Destacando o contexto de sala de aula, ainda que se planeje e disponha de recursos técnicos variados, o processo de ensino/aprendizagem se dá numa "condição de incerteza". Entre os assuntos e temas intrusos à programação cotidiana, salientam-se as questões de gênero e a sexualidade. Contudo, o autor ressalta o grande incômodo que esses temas trazem quando irrompem inadvertidamente o espaço da educação escolar (SEFFNER, 2011). Diante do não saber como lidar, acaba-se por se reproduzir posturas de contenção e normatização.

A problemática da sexualidade é um dos temas emergentes que fica parado na porta das escolas, pedindo para entrar e lá ser discutido. Isso provoca temores em muitos professores, pois no bojo do tema "sexualidade" costuma vir uma série de assuntos polêmicos e constrangedores: sexo, drogas, homossexualidade, promiscuidade, doença, agonia, morte, pecado, discriminação, masculino e feminino, entre outros. Em razão desses temores, associados e explicados em parte pela dificuldade da comunidade escolar em lidar com temas tão permeados por valores, e, por isso, delicados, os professores, muitas vezes, acabam por disseminar uma visão reducionista dos assuntos referentes à sexualidade. Estes assuntos comumente são apresentados como "perigosos", intimamente articulados a Doenças Sexualmente Transmissíveis (DSTs) e à gravidez indesejada, pautando-se, portanto, em uma visão higienista que reduz o corpo aos conceitos de assepsia, controle e prevenção, sendo o estudo do mesmo delegado ao campo da Biologia (REIS; RIBEIRO, 2005).

Todavia, como afirma Borillo (2009), a escola apresenta uma função importante, a qual deve exercer, em contraposição à intolerância. Vislumbrando o cumprimento dessa função, novos temas e problemas surgem todos os dias e não faltam pressões para que a escola "se encarregue" deles. A esse respeito, Castro; Abramovay; Silva (2004) referem que a maneira como a sexualidade é abordada na escola geralmente não contempla os anseios e as curiosidades das crianças e adolescentes. Isto sucede porque o enfoque é centralizado apenas no corpo biológico, não incluindo, dessa forma, os outros aspectos da sexualidade. Portanto, assume-se o princípio de que possibilitar que a escola discuta gênero e sexualidade em seu caráter multidimensional, implica que a formação do professor contemple esse aspecto.

\section{Objetivos}

O presente trabalho tem por objetivo apresentar a experiência de um Projeto de Extensão, iniciado no ano de 2005 e ainda em desenvolvimento, que pretende trabalhar questões relativas à sexualidade e gênero em escolas públicas, seja através de oficinas com adolescentes, seja na formação e assessoria a educadores vinculados à rede, bem como promover a formação de licenciandos do curso de ciências biológicas de uma universidade pública paulista do interior do estado, inseridos em semestres distintos do curso de graduação. Destaca-se que o curso em questão não possui, em sua grade curricular, nenhuma disciplina que aborde as questões de sexualidade e gênero para além do sexo biológico e que os sujeitos, futuros educadores, devem ser capazes de lidar com os temas em sala de aula. 
O projeto tem por metas: a) promover processos de educação sexual junto a jovens de escolas públicas, favorecendo a subjetivação de informações, a vivência segura e responsável da sexualidade, assim como o desenvolvimento do respeito à diversidade sexual e de gênero entre os jovens; b) colaborar para o desenvolvimento de práticas pedagógicas promotoras do respeito à diversidade sexual e de gênero; c) colaborar na formação continuada de professores qualificados para lidar com temas relativos à sexualidade e o gênero no cotidiano escolar; d) favorecer a formação inicial de professores capacitados para trabalhar com questões relativas à sexualidade e ao gênero.

\section{Trajetória metodológica de trabalho}

Os trabalhos desenvolvidos com os adolescentes dos anos finais do Ensino Fundamental e Ensino Médio, com faixa etária que varia entre os 13 e os 17 anos, pautam-se em oficinas, com frequência semanal (cerca de doze encontros semanais, no total), no contraturno escolar, em dias da semana variável, dependendo da organização e disponibilidade das diferentes escolas em receber o projeto. Ao longo do período de 2005 a 2015 (recorte de tempo utilizado para análise), foram desenvolvidas oficinas com cerca de 1500 adolescentes, conforme discutido em trabalho anteriormente publicado (SILVA; BRANCALEONI; OLIVEIRA, 2010). Neste artigo não serão analisados dados provenientes diretamente das produções realizadas pelos adolescentes nas oficinas e sim os registros dos trabalhos realizados pelos licenciandos nas escolas bem como os registros de supervisão.

O projeto de extensão tem como objetivos específicos: prover a clarificação de valores, por meio de um ambiente favorável à reflexão e expressão; fornecer informações sobre doenças sexualmente transmissíveis; possibilitar a subjetivação de informações acerca de sexualidade e gênero; promover o respeito à diferença e à diversidade; possibilitar que o adolescente se sinta responsável por suas escolhas. Também se oferece a possibilidade de grupos de formação de professores em que, também por intermédio de oficinas, trabalham-se temas relativos à sexualidade e gênero, assim como formas de se lidar com o tema no cotidiano da escola. Abre-se também a possibilidade aos educadores de busca de orientações mais pontuais com a busca por assessoria junto aos membros do projeto, em momentos que julgam necessária a colaboração do grupo para a reflexão com os alunos, na escola, acerca de suas ações. Como exemplo pode ser citado o minicurso ministrado aos docentes com parceria com a Diretoria Regional de Ensino do município, no ano de 2010 (AUGISTO; OLIEIRA, 2010).

Os grupos são coordenados por duplas de alunos, que já vivenciaram um processo de formação, em que eles experienciam as oficinas e temas que, posteriormente, desenvolverão nas escolas. Assim, pretende-se favorecer também a formação de futuros educadores mais capazes para o trabalho com o tema no seu cotidiano pedagógico. Pauta-se nos pressupostos das metodologias participativas, tendo como ponto de partida para as ações os sujeitos, para os quais estas são direcionadas. Dessa forma, os adolescentes e os professores de Ciências e Biologia inseridos na rede pública municipal e estadual, que compõem os grupos, são entendidos como agentes ao longo de todo o processo, visto que se busca ultrapassar a mera transmissão de informações, possibilitando o desenvolvimento da reflexão e a subjetivação dos conteúdos (SILVA, 2002). Assim, a intervenção é construída durante todo o processo, tendo como alicerce as demandas específicas de cada grupo. Cada encontro é registrado em diário de campo e discutido em supervisão com as docentes coordenadoras e demais alunos membros do projeto, material que será analisado no presente trabalho, dentro de uma abordagem qualitativa. A transcrição das discussões e de excertos dos diários de campo seguem o proposto por Marcuschi (1986).

\section{Os trabalhos desenvolvidos com os adolescentes}

Inicialmente aplica-se um instrumento para levantar os conhecimentos prévios de cada grupo, assim como os mitos, expectativas e dúvidas sobre sexualidade e gênero. Ao final dos trabalhos, realizase com os jovens uma avaliação acerca do processo vivenciado em grupo, elencando possíveis aprendizados e reflexões suscitadas ao longo desse.

Constata-se que o trabalho com os grupos de adolescentes, por meio das oficinas, favorece a aquisição de informações importantes sobre sexualidade, como indicam as falas: "eu aprendi sobre os métodos anticoncepcionais, que não é certo usar uma pílula só porque minha amiga usa, mas é importante ir ao médico"; "aprendi que não pode guardar a camisinha em qualquer lugar porque pode estragar"; "aprendi como coloca a camisinha".

Destaca-se também que as oficinas favorecem a reflexão e clarificação de crenças e valores sobre sexualidade e gênero, conforme se observa nas afirmações: "porque é difícil, se você fala que quer usar 
camisinha, seu namorado diz que você é puta, você precisa saber que não é, porque senão confunde e não faz usar"; "pensei mais nessas coisas que dizem que é de homem e dizem que é de mulher, já acho que não é bem assim".

Outro aspecto que pode ser apontado, como resultado do trabalho com os jovens, é o esclarecimento acerca das diferenças entre orientação sexual, identidade e expressão de gênero, conforme se identifica em falas como: "eu entendi que não é porque é gay vira mulher, são coisas diferentes".

Os relatos dos jovens também indicam o reconhecimento dos grupos como um espaço de diálogo franco, esclarecimento e reflexão, conforme se constata em colocações, tais como: "porque aqui a gente tem liberdade para perguntar o que não sabe, diferente da aula, dai a gente conversa e entende"; "porque assim a gente não tem vergonha de falar"; "a gente tem muita dúvida sobre sexualidade, mas não tem com quem falar, no grupo a gente conversou"; "a gente conversou sobre a primeira vez, coisas que a gente fica pensando, mas não sabe informação direito".

\section{Os trabalhos desenvolvidos com os educadores}

Foram desenvolvidas oficinas sobre e sexualidade e gênero com educadores da rede pública. Nelas pode-se constatar: a dificuldade dos educadores para trabalhar com o tema em sala de aula; a atribuição, por parte da escola, do desenvolvimento de temas de sexualidade e gênero exclusivamente aos professores de ciências e biologia; a redução ao caráter biológico e reprodutivo dos trabalhos desenvolvidos por esses professores; a presença de mitos, preconceitos e estereótipos em relação à sexualidade e ao gênero; o desejo de que a educação sexual fosse responsabilidade unicamente da família; a confusão entre sexo biológico, orientação sexual, identidade e expressão de gênero.

Ao longo dos encontros, as questões acima mencionadas foram sendo problematizadas e refletidas, abrindo-se espaços para que houvesse dúvidas acerca de crenças e padrões assumidos como naturais. Notou-se ainda o reconhecimento de preconceitos e processos de discriminação que ocorrem na escola. Assim, as oficinas se mostraram espaços promissores para a subjetivação de informações, bem como para a reflexão, clarificação e transformação de valores e crenças também no trabalho com os educadores.

Além das oficinas, foram realizadas ações de acompanhamento do trabalho de professores no planejamento e desenvolvimento de atividades sobre sexualidade e gênero, assim como foram oferecidos espaços de supervisão àqueles que desenvolviam trabalhos sobre os temas. Constatou-se: a ausência de espaços formativos, nas escolas, para que o trabalho de educação sexual dos jovens fosse desenvolvido com mais segurança e qualificação, de forma menos normativa e biologizante; a inexistência de espaços de interlocução e reflexão entre os professores sobre o trabalho com os temas; a importância da promoção de espaços de reflexão do fazer docente na educação sexual de jovens; a contribuição oferecida pela assessoria e supervisão para a reflexão e transformação da prática docente com temas referentes à sexualidade e ao gênero.

\section{A função do Projeto na formação inicial de professores}

Quanto à contribuição do projeto para a formação inicial de educadores mais capacitados para o trabalho com questões referentes à sexualidade e ao gênero, temos a formação de cerca de 150 multiplicadores, ou seja, graduandos que vivenciaram as oficinas e discussões teóricas, estando capacitados para desenvolver trabalhos de educação sexual junto a outros grupos. Sobre a função da participação do Projeto em suas formações profissionais, destacaram a carência desses temas na matriz curricular. Salienta-se, ainda, a importância da participação no Projeto de Extensão como meio de superação das mesmas, bem como indica-se a mobilização de saberes relacionados ao domínio do conteúdo, sendo, portanto constitutivo de sua formação profissional. Conforme o relato: - "aprendi muito sobre o tema sexualidade, pude mudar vários conceitos errados que apresentava sobre esse tema e quebrar preconceitos que possuía."

Além de conhecimentos ligados aos conteúdos, os participantes também destacaram o desenvolvimento de uma postura docente de "escuta" dos conceitos e preconceitos prévios do aluno, de modo a promover a discussão e a reflexão em sala de aula, rompendo com o lugar do suposto saber e normatização, favorecendo a subjetivação das informações, bem como a vivência mais responsável e segura da sexualidade. Como observa-se na fala: "Aprendi, a partir dos conceitos prévios de cada turma, 
a lidar com os assuntos de várias maneiras diferentes, olhar de vários ângulos, não dar minha opinião pessoal e mostrar todas as variáveis, responder "não sei' e entregar a resposta no próximo encontro."

Os relatos de participantes indicam essa transformação em suas posturas, conforme se observa nesta fala: "pude identificar que cada turma é única e que não podia aplicar a mesma dinâmica e esperar que esta seja significativa para todas [...]".

Indica-se, ainda, que uma das contribuições significativas da participação no projeto foi o desenvolvimento da condição de reconhecimento dos próprios preconceitos, conforme se podem constatar nos posicionamentos seguintes: "Durante as discussões e orientações eu percebi que apresentava vários preconceitos sobre temas discutidos, por exemplo, a homossexualidade."; "Eu tive a dimensão de que os preconceitos vão muito além disso, estão em cada pequeno pensamento de intolerância ao diferente. E ainda, não é pelo fato de tolerar e aceitar que necessariamente deixei de ter preconceito. Em verdade me descobri uma mulher com muitos preconceitos e o grupo me ajuda constantemente a questioná-los".

Para além do reconhecimento dos preconceitos, os universitários afirmam perceberem rupturas em relação aos mesmos, como quando afirmam: "Por tratar muito da questão dos preconceitos com os alunos, nós primeiro tivemos que, na medida do possivel, lidar com nossos próprios preconceitos."; "As discussões durante nosso trabalho nas escolas e, principalmente, durante a formação me fez respeitar as opiniões diferentes das minhas, entender seus motivos. Dessa forma, hoje tenho uma visão menos preconceituosa."

Reportam-se a transformações em suas ações diante de situações, nas quais anteriormente agiam de forma estereotipada e preconceituosa. Assim relatam: "Aprendi a ouvir mais o outro, a pensar e ver as coisas sob outra perspectiva. Os julgamentos deixaram de ser a priori"; "Promoveu o entendimento da necessidade do debate do tema sexualidade não apenas nos espaços formais de educação, como também nos espaços não formais."

Constata-se, portanto, a condição de superação da reflexão racional, envolvendo-se os universitários de maneira integral, contemplando as formas de pensar, sentir e agir.

\section{Conclusões}

As experiências de trabalho no Projeto salientam as dificuldades enfrentadas pelos educadores no trabalho com temas referentes a sexualidade e gênero no cotidiano escolar, ressaltando a importância de se cuidar desse aspecto na formação inicial dos educadores de forma clara e assumida nos projetos político-pedagógicos. Outra questão que merece destaque é a importância de se priorizar metodologias de trabalho que favoreçam o diálogo, a livre expressão, a reflexão e a construção, na medida em que a mera transmissão de informações não sustenta a promoção de uma educação sexual promotora do respeito à diversidade sexual e de gênero.

Conclui-se que as ações do projeto com adolescente, educadores e mesmo com universitários favorecem reflexões importantes sobre sexualidade e gênero, colaborando para a promoção do respeito aos diversos e da vivência da sexualidade de forma mais refletida e responsável.

O projeto em questão se sustenta por pilares alicerçados na compreensão de sexualidade, que é um processo contínuo de construção humana, muito além da prática sexual, mas que constitui a própria identidade do sujeito por meio das relações que estabelecem com o outro, com o próprio corpo e com o prazer. Assim, visa-se favorecer processos formativos que rompam com visões estereotipadas e biologizantes da sexualidade, superando a visão higienista que predomina nos processos educacionais escolares.

Para tanto, pensou-se um projeto que favorecesse o desenvolvimento dessa perspectiva acerca da sexualidade. Destaca-se também a importância atribuída à indissociabilidade ensino/pesquisa/extensão tanto nos objetivos que fundamentam suas ações, quando no seu desenvolvimento ao longo dos anos de sua existência.

A experiência com o projeto indica para a importância da perspectiva metodológica que assume o processo de ensino/aprendizagem, no ensino superior, fundamentado no tripé ensino/pesquisa/ extensão. Trata-se de uma condição de construção contínua de conhecimento entre parceiros, que ocupam funções distintas, contudo não subjugadas.

O conhecimento compreendido como um processo de construção contínua, em uma relação dialética teoria/prática, oportuniza a ruptura com conceitos institucionalizados, normatizações e normalizações, em que a sexualidade é reduzida a uma compreensão biologicista e higienista. 


\section{Referências}

Augusto, T. G. S.; OLIVEIRA, R. R.; Mouro, B. C.; Castro, N. B. L. de; Oliveira, R. H. Uma experiência na formação continuada para professores de ciências nas escolas públicas estaduais de Jaboticabal SP. Revista da SBEnBIO, v. 3, p. 1533-1542, 2010.

BENTO, B. Na escola se aprende que a diferença faz a diferença. Rev. Estud. Fem., Florianópolis, v. 19, n. 2, ago. 2011. Disponível em: <http://www.scielo.br/scielo.php?script=sci_arttext\&pid=S0104026X2011000200016\&lng=pt\&nrm=iso>. Acesso em: 10 de mar. de 2016.

BORILlO, D. A Homofobia. In: LIONÇO, T.; DINIZ, D. (Org.). Homofobia \& Educação: um desafio ao silêncio. Brasília: Letras Livres: EdUnB, 2009. p. 15-46.

CASTRO, M. G.; ABRAMOVAY, M. ; SILVA, L. B. da. Juventudes e sexualidade. Brasília: UNESCO, Brasil, 2004.

MARCUSCHI, L. A. Análise da conversação. São Paulo: Ática, 1986. (Série Princípios).

REIS, G. V.; RIBEIRO, P. R. M. Sexualidade e educação escolar: algumas reflexões sobre orientação sexual na escola. In: Bortolozzi, A. C.; Maia, A. F. (Orgs.). Sexualidade e infância. Série Cadernos Cecemca, v. 1. Bauru: FC/UNESP: CECEMCA, 2005.

SEFFNER, F. Um bocado de sexo, pouco giz, quase nada de apagador e muitas provas: cenas escolares envolvendo questões de gênero e sexualidade. Rev. Estud. Fem., Florianópolis, v. 19,n. 2, ago. 2011. Disponível em: <http://www.scielo.br/scielo.php?script=sci_arttext\&pid=S0104026X2011000200017\&lng=pt\&nrm=iso >. Acesso em 27 out. 2015.

SILVA, C. S.F.; BRANCALEONI, A.P. L.; OLIVEIRA, R. R. Oficinas sobre sexualidade com adolescentes: um estudo de caso. Experiências em Ensino de Ciências - v. 5, n.2, p. 163-175, 2010.

SILVA, R. C. Metodologias Participativas para Trabalhos de Promoção de Saúde e Cidadania. São Paulo: Vetor. 2002.

Recebido para publicação em 30/5/2016 e aprovado em 9/9/2016. 